\title{
Carbachol Inhibits Insulin-Stimulated Phosphatidylinositol 3-Kinase Activity in SH-SY5Y Neuroblastoma Cells
}

\author{
Yaakov Lavie and Bernard W. Agranoff \\ Neuroscience Laboratory, University of Michigan, Ann Arbor, Michigan, U.S.A.
}

\begin{abstract}
SH-SY5Y human neuroblastoma cells express muscarinic $M_{3}$ receptors as well as insulin receptors, thus offering the opportunity to investigate possible cross-talk following activation of two distinct intracellular signal transduction pathways that convert the precursor phosphatidylinositol (PI) to its $3^{\prime}$ phosphate or its $4^{\prime}$ phosphate, respectively. In this study, the effect of carbachol on insulin-stimulated PI 3-kinase (PI3K) activity was examined in SH-SY5Y cells. Insulin addition to the cell medium induced a 10-26-fold increase in anti-phosphotyrosine-immunoprecipitable PI3K activity. Preincubation with $1 \mathrm{mM}$ carbachol inhibited the insulin-stimulated PI3K activity in a time-dependent manner, with half-maximal and maximal inhibition times of 4 and $15 \mathrm{~min}$, respectively. Atropine blocked the inhibitory effect of carbachol. Although carbachol did not change the amount of $85-\mathrm{kDa}$ subunit protein regulatory unit associated with tyrosinephosphorylated proteins, either in control or in insulinstimulated cells, it appears to decrease the amount of associated $110-\mathrm{kDa}$ catalytic subunit protein in the latter instance. Because PI3K activity from SH-SY5Y cells has been shown to be inhibited in vitro in the presence of cytidine diphosphodiacylglycerol (CDP-DAG) or phosphatidate (PA), we examined the presence of these lipids in SH-SY5Y cells that had been treated with carbachol. Formation of both lipids was increased in a time-dependent manner following carbachol addition, and their increased levels are proposed to account for the observed in vivo inhibition of PI3K. Addition of the cell-permeable homologue didecanoyl-CDP-DAG to intact cells inhibited insulin-stimulated PI3K activity up to $75 \%$, with an $\mathrm{IC}_{50}$ of $0.5 \mu \mathrm{M}$, a result that further supports a proposed lipidmediated inhibition of $P \mid 3 K$. Exogenously added didecanoyl-PA, however, did not affect PI3K activity. The possibility that stimulation of the PI 4-kinase-mediated signal transduction pathway leads to down-regulation of the PI3K-mediated signal transduction pathway in vivo, via inhibition of PI3K by CDP-DAG or by other consequences of phosphoinositidase $\mathrm{C}$-linked receptor activation, is discussed. Key Words: Carbachol-Insulin-Phosphatidylinositol 3-kinase-Cytidine diphosphodiacylglycerol-Phosphatidate-SH-SY5Y neuroblastoma cells. J. Neurochem. 67, 1245-1251 (1996).
\end{abstract}

Phosphatidylinositol (PI) 3-kinase (PI3K) mediates a central downstream signal transduction route for vari- ous growth factors, including cytokines, epithelial growth factor, platelet-derived growth factor, insulin, insulin-like growth factors (IGFs), and nerve growth factor (NGF) (Parker and Waterfield, 1992), and is permissive for several cellular responses, including mitogenesis (Rodriguez-Viciana et al., 1994), translocation of glucose transporters (Clarke et al., 1994), and differentiation (Carter and Downes, 1993). The enzyme is able to phosphorylate PI, PI 4-phosphate (PI4P), and PI 4,5-bisphosphate $\left[\mathrm{PI}(4,5) \mathrm{P}_{2}\right]$ on the $3^{\prime}$ position of the inositol ring in vitro, yielding in each instance the 3-phosphate of the corresponding lipid (Panayotou and Waterfield, 1992; Parker and Waterfield, 1992). In vivo, $\mathrm{PI}(4,5) \mathrm{P}_{2}$ is the favored substrate (Hawkins et al., 1992). The mechanism by which insulin activates PI3K involves induction of insulin receptor tyrosine kinase activity followed by tyrosine phosphorylation of insulin receptor substrate 1 (IRS-1). Tyrosine-phosphorylated residues within IRS-1 then associate with specific src homology domains of various target proteins, including PI3K ( $\mathrm{My}-$ ers et al., 1994). The recruitment of PI3K holoenzyme [containing both the $85-\mathrm{kDa}(\mathrm{p} 85)$ regulatory subunit and the $110-\mathrm{kDa}(\mathrm{p} 110)$ catalytic subunit] results in the enzyme's activation. p85 is thought to act as an adapter protein that couples the p1 10 catalytic subunit

Received November 15,1995 ; revised manuscript received March 28, 1996; accepled April 15, 1996.

Address correspondence and reprint requests to Dr. B. W. Agranoff at Neuroscience Laboratory, University of Michigan, I I03 East Huron Street, Ann Arbor, MI, 48104-1687, U.S.A.

The present address of Dr. Y. Lavie is John Wayne Cancer Institute, 2200 Santa Monica Boulevard, Santa Monica, CA 90404. U.S.A.

Abbreviations used: CDP-DAG, cytidine diphosphodiacylglycerol; DAG, diacylglycerol; IGF, insulin-like growth factor; IRS-1, insulin receptor substrate-1; NGF, nerve growth factor; $\mathrm{p} 85,85-\mathrm{kDa}$ regulatory subunit of phosphatidylinositol 3-kinase; pl 10, 110-kDa catalytic subunit of phosphatidylinositol 3-kinase; PA, phosphatidate; PBS, phosphate-buffered saline: PI, phosphatidylinositol; PI3K, phosphatidylinositol 3-kinase: PI3P, phosphatidylinositol 3phosphate; PI4K, phosphatidylinositol 4-kinase; PI4P, phosphatidylinositol 4-phosphate; $\mathrm{PI}(4,5) \mathrm{P}_{2}$, phosphatidylinositol 4,5-bisphosphate; SDS-PAGE, sodium dodecyl sulfate-polyacrylamide gel electrophoresis. 
to tyrosine phosphoproteins via an $\mathrm{SH} 2$ domain ( $\mathrm{Hu}$ and Schlessinger, 1994).

In the present study we used SH-SY5Y human neuroblastoma cells, which express insulin receptors (Mattsson et al., 1990) as well as muscarinic $\mathrm{M}_{3}$ receptors (Offermanns et al., 1993), to examine PI3K activity following exposure of the cells to both insulin and carbachol. This investigation was prompted by a prior study in which we demonstrated that phosphatidate (PA) and cytidine diphosphodiacylglycerol (CDPDAG) each block PI3K in vitro (Lavie and Agranoff, 1996). These two lipids are sequential biosynthetic precursors of PI, the common lipid substrate for both PI3K and PI 4-kinase (PI4K) (Fisher et al., 1992). It was furthermore known that labeled CDP-DAG levels are elevated during carbachol-stimulated phosphoinositide turnover cycle [which uses the PI4K pathway in these cells (Heacock et al., 1993)]. The question was thus raised of whether or not ligand-stimulated breakdown of PI(4,5) $P_{2}$ and its associated resynthesis via PA and CDP-DAG would affect stimulation of the PI3K-mediated pathway in vivo. Because insulin induces a mitogenic response and enhances neurite formation in SH-SY5Y cells (Recio-Pinto and Ishii, 1988; Mattsson et al., 1990), it was chosen for investigation of the possible effects of carbachol-stimulated activation of the PI4K pathway on the PI3K pathway in these cells.

The present results indicate that elevated intracellular CDP-DAG content resulting from stimulated $\mathrm{PI}(4,5) \mathrm{P}_{2}$ breakdown may contribute to regulation of the PI3K-directed signal transduction pathway in vivo. During the course of these studies, it was found that carbachol addition to insulin-stimulated cells leads to selective loss of p1 10 from the phosphotyrosine immunocomplex, indicating a possible additional mechanism for interaction of the two signal transduction pathways.

\section{EXPERIMENTAL PROCEDURES}

\section{Materials}

ATP, bovine serum albumin, carbachol, insulin from bovine pancreas, leupeptin, aprotinin, and PI from bovine liver were purchased from Sigma ( St. Louis, MO, U.S.A.). Didecanoyl-PA was the product of Serdary Research Labs (London, Ontario, Canada). Didecanoyl cytidine diphosphodiacylglycerol $\left(\mathrm{C}_{10^{-}}\right.$CDP-DAG $)$was the gift of A. K. Hajra. [ $\gamma-$ $\left.{ }^{32} \mathrm{P}\right] \operatorname{ATP}(3,000 \mathrm{Ci} / \mathrm{mmol})$ and $\left[{ }^{3} \mathrm{H}\right]$ cytidine $(30 \mathrm{Ci} / \mathrm{mmol})$ were from DuPont NEN (Wilmington, DE, U.S.A.) . Carrierfree ${ }^{32} \mathrm{P}_{\mathrm{i}}$ was purchased from ICN Pharmaceuticals (Costa Mesa, CA, U.S.A.). Silica gel 60 TLC plates were from Merck (Darmstadt, Germany). Dulbecco's modified Eagle's medium, fetal bovine serum, and protein A-agarose were purchased from GibcoBRL (Gaithersburg, MD, U.S.A.). Anti-rat PI3K (anti-p85) and anti-phosphotyrosine (monoclonal $\operatorname{IgG} 2 \mathrm{~b}_{\mathrm{k}}$ ) antibodies were from Upstate Biotechnology (Lake Placid, NY, U.S.A.). Anti-p1 10 antibodies were purchased from Santa Cruz Biotechnology (Santa Cruz, CA, U.S.A.).

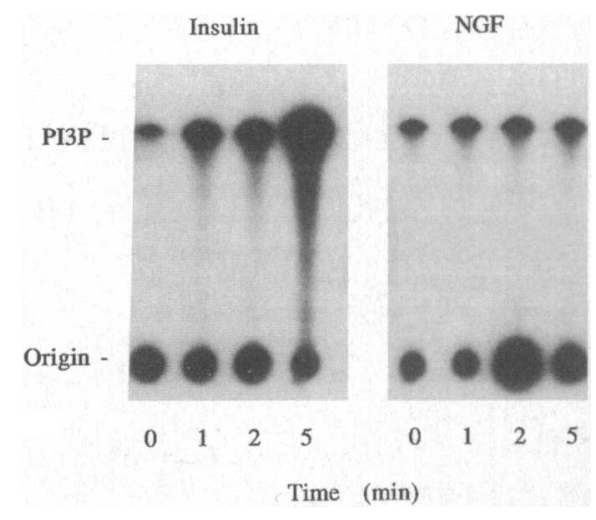

FIG. 1. Insulin and NGF stimulate PIBK activity in anti-phosphotyrosine immunoprecipitates of $\mathrm{SH}-\mathrm{SY} 5 \mathrm{Y}$ cells. Cells were grown as described in Experimental Procedures. Insulin (100 $\mathrm{nM}$ ) or NGF (100 nM) was added to the medium and incubated for the indicated times at $37^{\circ} \mathrm{C}$. Lysates were immunoprecipitated with anti-phosphotyrosine antibodies, and PI3K activity was measured as described in Experimental Procedures. Autoradiographs of the TLC of PIP are from one of three experiments that gave similar results.

\section{Cell culture}

SH-SY5Y human neuroblastoma cells (passages 60-80) were grown in Dulbecco's modified Eagle's supplemented with $10 \%$ fetal bovine serum at $37^{\circ} \mathrm{C}$ in a humidified atmosphere containing $10 \% \mathrm{CO}_{2}$. For all the experiments using effectors (insulin, carbachol, etc.), cells were preincubated for $24 \mathrm{~h}$ in Dulbecco's modified Eagle's medium supplemented with $0.1 \%$ bovine serum albumin.

\section{Immunoprecipitation of PI3K activity from stimulated cells using anti-phosphotyrosine antibodies}

Cells were grown in 150-mm-diameter dishes. Effectors were directly added to the medium, and the cells were incubated for the indicated times at $37^{\circ} \mathrm{C}$. After hormonal treat ment, the medium was aspirated, and the cells were washed twice with $15 \mathrm{ml}$ of ice-cold phosphate-buffered saline (PBS; pH 7.4) before addition of $1 \mathrm{ml}$ of buffer B [137 $\mathrm{m} M$ $\mathrm{NaCl}, 20 \mathrm{~m} M$ Tris-HCl ( $\mathrm{pH} 8.0$ ), $1 \mathrm{~m} M$ EDTA, $1 \mathrm{~m} M$ $\mathrm{MgCl}_{2}, 1 \mathrm{mM} \mathrm{CaCl}_{2}, 10 \%$ glycerol, $1 \%$ Nonidet $\mathrm{P}-40$. 10 $\mu \mathrm{g} / \mathrm{ml}$ of leupeptin, $2 \mu \mathrm{g} / \mathrm{ml}$ of aprotinin, $1 \mathrm{~m} M$ phenylmethyisulfonyl fluoride, and $1 \mathrm{~m} M$ sodium orthovanadate $\mid$. The cells were scraped free from the dishes and centrifuged at $6,000 \mathrm{~g}$ for $10 \mathrm{~min}$ in a $15-\mathrm{ml}$ conical polystyrene centrifuge tube (Sardstet). The resulting supernatant was incubated overnight at $4^{\circ} \mathrm{C}$ with $5 \mu \mathrm{g}$ per tube of anti-phosphotyrosine antibodies, followed by addition of protein A-agarose beads for $2 \mathrm{~h}$. Immune complexes bound to the beads were washed three times with cold PBS ( $\mathrm{pH} 7.4$ ) containing $1 \%$ Nonidet P-40, twice with PBS containing $0.5 \mathrm{M} \mathrm{LiCl}$ and $0.1 \mathrm{M}$ Tris$\mathrm{HCl}(\mathrm{pH} 7.5)$, and twice with $10 \mathrm{~m} M$ Tris- $\mathrm{HCl}(\mathrm{pH} 7.5)$ containing $0.1 M \mathrm{NaCl}$ and $1 \mathrm{~m} M$ EDTA.

\section{PI3K assay}

The reaction mixture for measuring PI3K activity contained $100 \mu \mathrm{l}$ of the enzyme and $50 \mu \mathrm{l}$ of PI micelles that were prepared by sonicating $800 \mu \mathrm{g}$ of PI in $1 \mathrm{ml}$ of $20 \mathrm{~m} M$ HEPES buffer ( $\mathrm{pH} 7.6$ ) containing $1 \mathrm{~m} M$ EDTA for $45 \mathrm{~s}$ (Kontes sonicator with a microtip probe). The mixture was preincubated for $15 \mathrm{~min}$ at room temperature, and the reaction was 
started by addition of $50 \mu \mathrm{l}$ of $40 \mathrm{mM} \mathrm{MgCl}_{2}$ containing $200 \mu M\left[\gamma^{-}{ }^{32} \mathrm{P}\right] \mathrm{ATP}(20 \mu \mathrm{Ci}$ per assay $)$. The reaction was terminated after $15 \mathrm{~min}$ by addition of $750 \mu \mathrm{l}$ of ice-cold $\mathrm{CHCl}_{3} /$ methanol $/ 2 \mathrm{M} \mathrm{HCl}$ (20:40:0.5 by volume) followed by $250 \mu \mathrm{l}$ of chloroform and $250 \mu \mathrm{l}$ of $2 \mathrm{M} \mathrm{HCl}$. The resulting organic phase and the interface were extracted with an equal volume of methanol $/ 0.1 M$ EDTA (1:0.9 vol/vol). The organic phase was dried, resuspended in $25 \mu \mathrm{l}$ of chloroform $/$ methanol $(1: 1 \mathrm{vol} / \mathrm{vol})$, and spotted on a TLC plate that was precoated with $1 \%$ potassium oxalate. The plate was developed in $\mathrm{CHCl}_{3} /$ methanol/water/7.7 $M \mathrm{NH}_{4} \mathrm{OH}$ (60:47:11.3:2 by volume) (Serunian et al., 1991). ${ }^{32}$ P-Labeled PI 3-phosphate (PI3P) was visualized by autoradiography and compared with iodine-stained PI phosphate marker, for which PI4P was used. Radioactivity in this spot was quantificd as described in Experimental Procedures. Although PI3P and PI4P are not separated by this procedure, the possibility that PI4K activity was present was excluded on the basis of susceptibility to wortmannin and to Nonidet P-40 detergent.

\section{Immunoblotting of the p85 subunit of PI3K}

Cells, treated with various elfectors, were lysed, followed by immunoprecipitation with anti-phosphotyrosine antibodies as described above. After washing, immune complexes were resolved on $7.5 \%$ sodium dodecyl sulfate-polyacrylamide gel electrophoresis (SDS-PAGE). Separated proteins were transferred to nitrocellulose paper and analyzed for the presence of the $\mathrm{p} 85$ by protein immunoblot, using anti-p 85 antiserum. Bound antibodies were visualized by an enhanced chemiluminescence (ECL) detection system, using horseradish peroxidase conjugated to anti-rabbit $\operatorname{IgG}$ as the secondary antibody (Amersham). In a separate series of experiments, gels were reprobed with anti-pl 10 antibody.

\section{Radiolabeling studies}

Cells were labeled with either ${ }^{32} \mathrm{P}_{\mathrm{i}}$ or $\left[{ }^{3} \mathrm{H}\right]$ cytidine in oxygenated buffer $\mathrm{A}(142 \mathrm{~m} M \mathrm{NaCl}, 5.6 \mathrm{~m} M \mathrm{KCl}, 2.2 \mathrm{~m} M$ $\mathrm{CaCl}_{2}, 3.6 \mathrm{~m} M \mathrm{NaHCO}_{3}, 1 \mathrm{~m} M \mathrm{MgCl}_{2}, 5.6 \mathrm{~m} M$ glucose, and $30 \mathrm{~m} M$ HEPES, $\mathrm{pH}$ 7.4). To label PA, cells grown in 60)-mm-diameter culture dishes were washed twice with buffer $\mathrm{A}$ and preincubated in $5 \mathrm{ml}$ of the same buffer containing $20 \mu \mathrm{Ci}$ of ${ }^{32} \mathrm{P}$ per dish for $10 \mathrm{~min}$ at $37^{\circ} \mathrm{C}$. To label CDP-DAG, cells were washed as above and incubated in 5 $\mathrm{ml}$ of buffer A containing $10 \mu \mathrm{Ci}$ of $\left[{ }^{3} \mathrm{H}\right]$ cytidine per dish for $1 \mathrm{~h}$ at $37^{\circ} \mathrm{C}$. Following addition of the effectors for various time points, reactions were terminated on ice by aspirating the medium and adding $1 \mathrm{ml}$ of ice-cold methanol $/ 1 \mathrm{M}$ $\mathrm{HCl}$. The cells were scraped free from the dishes and translerred to glass test tubes. Lipids were extracted from the cell pellet by adding $1 \mathrm{ml}$ each of water and chloroform, followed by vortex-mixing. The lower chloroform phase was dried with a Speed Vac and resuspended in $25 \mu \mathrm{l}$ of chloroform/ methanol ( $1: 1$ vol/vol). Lipids extracts were spotted on a 20) $\times 20-\mathrm{cm}$ TLC plate and were developed in a $\mathrm{CHCl}_{3} /$ $\mathrm{CH}_{3} \mathrm{OH} /$ acetic acid/acetone/water $(40: 13: 12: 15: 8$ by volume) solvent system. The plate was subjected to autoradiography, and the radioactive bands were identified by cochromatography with authentic standards. TLC spots of the radioaclive lipids were scraped off into counting vials, and radioactivity was determined by liquid scintillation counting.

\section{RESULTS}

Stimulation of PI3K activity associated with antiphosphotyrosine immunoprecipitates in SH-SY5Y cells is induced by insulin and NGF

Activation of PI $3 \mathrm{~K}$ is generally correlated with an increase in the amount of PI3K activity that can be immunoprecipitated with anti-phosphotyrosine antibodies. We found that in SH-SY 5 Y cells, insulin and NGF are each able to induce such an enzyme activation. As shown in Fig. 1, insulin induced a rapid increase in anti-phosphotyrosine-precipitable PI3K activity, which was clearly visible by $1 \mathrm{~min}$ and was maximal by 5 min. The response was transient and decreased thereafter (data not shown). Although the kinetics of stimulation by NGF were very similar, NGF's potency was much lower (threefold stimulation, compared with 20-fold).

\section{Carbachol inhibits insulin-stimulated PI3K activity}

We examined the effect of the muscarinic ligand carbachol on the activation of PI3K by insulin. Pretreatment of SH-SY5Y cells with $1 \mathrm{~m} M$ carbachol for 30 min markedly reduced the elevation in PI3P content produced by PI3K from insulin-stimulated cells (Fig. 2). PI3P content was also lower compared with control basal levels after treatment with carbachol alone. The inhibitory effect elicited by carbachol was blocked by preincubation of the cells with the muscarinic antagonist atropine, demonstrating that the effect of carbachol was receptor mediated. Figure 3 shows that the inhibition of insulin-induced PI3K activity by carbachol is time dependent. As preincubation time increased, enzyme-stimulated activity decreased, with half-maximal and maximal times of 4 and 15 min, respectively.

\section{Investigation of possible mechanisms by which carbachol inhibits insulin-stimulated PI3K activity}

Because PI3K is activated in insulin-stimulated cells by the binding of its $p 85$ to tyrosine-phosphorylated

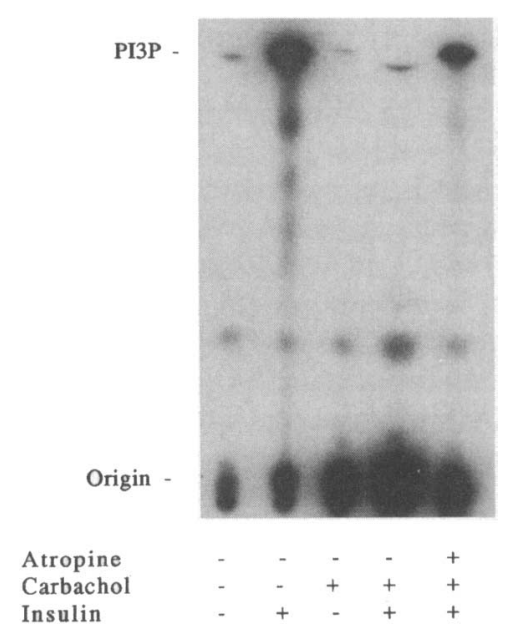

FIG. 2. Carbachol inhibits insulin-stimulated PI3K activity. Cells were preincubated for 10 min without or with atropine $(10 \mu \mathrm{M})$ and then for an additional $30 \mathrm{~min}$ in the absence or presence of $1 \mathrm{~m} M$ carbachol, followed by addition of $100 \mathrm{nM}$ insulin for 5 min. Cellular extracts were then reacted with anti-phosphotyrosine antibodies and assayed for PI3K activity as described in Experimental Procedures. Carbachol produced an $87 \%$ decrease in this experiment, somewhat higher than the average inhibition seen in three experiments $(56 \%)$ 


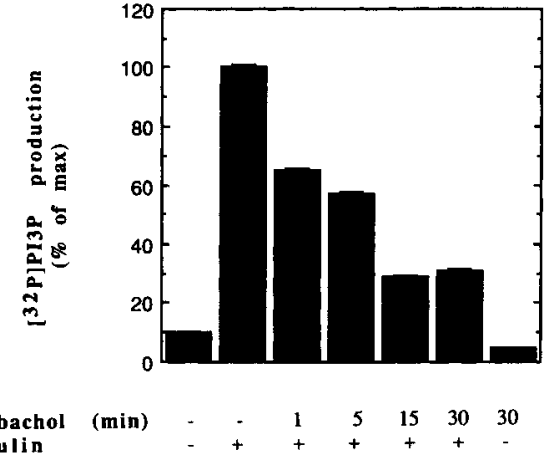

FIG. 3. Time dependence of carbachol inhibition of insulin-stimulated PI3K activation. Cells were treated with or without $(1 \mathrm{mM})$ carbachol for the indicated times and then for an additional 5 min with $100 \mathrm{nM}$ insulin, as indicated. Anti-phosphotyrosine immunoprecipitates were assayed for PI3K activity as described in Experimental Procedures. The phosphorylated lipid products were separated by TLC, and the corresponding PI phosphate band was scraped into vials and counted for radioactivity. $\mathrm{P} \mid 3 \mathrm{~K}$ activity is calculated as a percentage of insulin-stimulated, uninhibited kinase activity $(100 \%=7,091 \pm 430 \mathrm{cpm})$. Data are mean $\pm S D$ (bars; half the range) values of duplicate determinations and are typical of three experiments.

proteins, we examined the possibility that carbachol interferes directly with this interaction. Cells were treated with carbachol and/or insulin for 30 and $5 \mathrm{~min}$, respectively. Whole cell lysates were then subjected to immunoprecipitation with anti-phosphotyrosine antibodies, and the immunoprecipitates were analyzed by western blotting with anti-p85 antibodies. As shown in Fig. 4, p85 association with tyrosine-phosphorylated proteins is greatly enhanced in cells treated with insulin. Carbachol affected neither the control level of $p 85$ nor the insulin-stimulated association of p85 with tyrosine-phosphorylated proteins (lane 4 ). The tentative conclusion that the observed inhibitory effect of carbachol on insulin-induced PI3K activation does not involve changes in binding of the heterodimer to tyrosine-phosphorylated protein was, however, challenged by further studies in which such gels were reprobed with anti-p1 10 antibodies. In contrast to the lack of effect seen on $\mathrm{p} 85$ binding, a significant decrease $(54 \%)$ in amount of anti-p1 10-immunoreactive material in insulin-stimulated cells was seen in the presence of carbachol, as is further addressed in Discussion.

Because CDP-DAG and PA inhibit SH-SY5Y cellderived PI3K activity in vitro (Lavie and Agranoff, 1996), it was of interest to examine the possibility that a carbachol-induced increase in CDP-DAG content could contribute to our in vivo findings. We first characterized the time course by which carbachol stimulates the formation of CDP-DAG and PA in SH-SY5Y cells. To assess changes in PA level, cells were incubated briefly with ${ }^{32} \mathrm{P}_{\mathrm{i}}$ before addition of carbachol. The time course of labeled PA accumulation was then followed for $30 \mathrm{~min}$. As shown in Fig. 5, labeled PA content is dramatically elevated as early as $1 \mathrm{~min}$ after

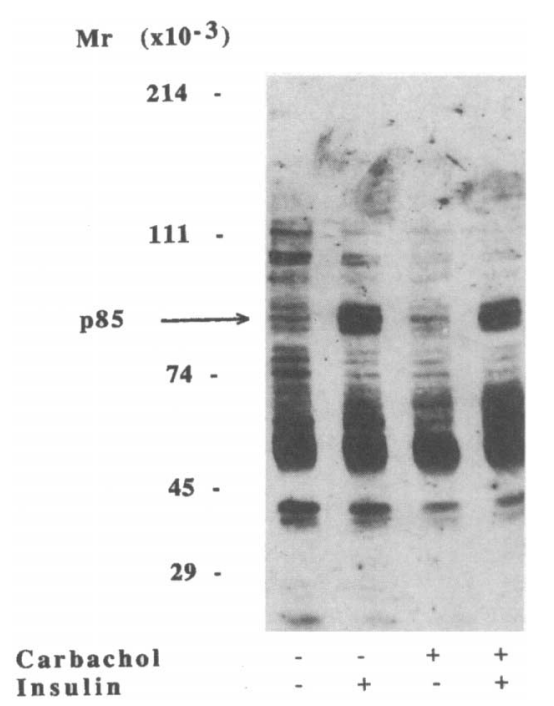

FIG. 4. Detection of $\mathrm{PI} 3 \mathrm{~K}$ in anti-phosphotyrosine immunoprecipitates by western blotting. Cells were treated for 30 min with or without $1 \mathrm{mM}$ carbachol and then for an additional 5 min with or without $100 \mathrm{nM}$ insulin, as indicated. The cellular extracts were immunoprecipitated with anti-phosphotyrosine antibodies, subjected to $7.5 \%$ SDS-PAGE, and then immunoblotted, using anti-p85 antibodies, as described in Experimental Procedures. The prominent spots above the $45-\mathrm{kDa}$ mark represent IgGs.

addition of $1 \mathrm{~m} M$ carbachol and is maximal within 5 min, presumably reflecting phosphorylation of diacylglycerol (DAG) by DAG kinase. Similarly, addition of carbachol to $\left[{ }^{3} \mathrm{H}\right]$ cytidine-prelabeled cells results in a drastic increase (up to fivefold) in amount of $\left[{ }^{3} \mathrm{H}\right]$ CDP-DAG compared with the control level. Carbachol elicits a half-maximal increase in $\left[{ }^{3} \mathrm{H}\right]$ CDP-DAG level

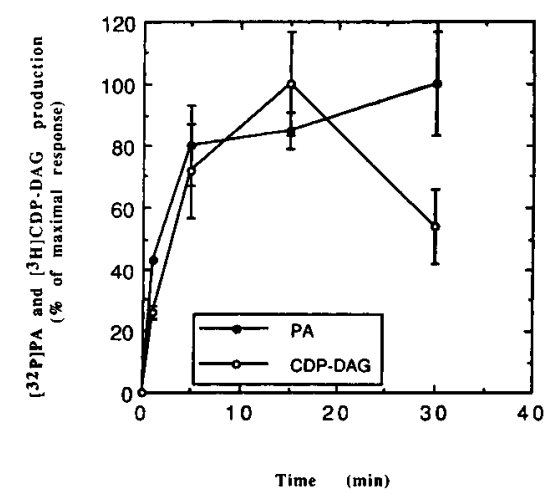

FIG. 5. Time-dependent accumulation of $\left[{ }^{3} \mathrm{H}\right] \mathrm{CDP}-\mathrm{DAG}$ and $\left[{ }^{32} \mathrm{P}\right] \mathrm{PA}$ in carbachol-stimulated cells. SH-SY5Y cells were prelabeled with either ${ }^{32} \mathrm{P}_{\mathrm{i}}$ or $\left[{ }^{3} \mathrm{H}\right]$ cytidine, treated with $1 \mathrm{mM}$ carbachol for the times indicated, and analyzed for $\left[{ }^{3} \mathrm{H}\right] \mathrm{CDP}-\mathrm{DAG}$ and $\left[{ }^{32} \mathrm{P}\right] \mathrm{PA}$ as described in Experimental Procedures. Data are mean \pm SEM (bars) values from two separate experiments, expressed as percentages of the maximal response for each lipid $\left(100 \%=5,870 \pm 1,003\right.$ and $215,800 \pm 38,220 \mathrm{cpm}$ for $\left[{ }^{3} \mathrm{H}\right]-$ CDP-DAG and [ $\left.{ }^{32} \mathrm{P}\right] \mathrm{PA}$, respectively). The zero-time radioactivity level for $\left[{ }^{3} \mathrm{H}\right] \mathrm{CDP}-\mathrm{DAG}$ was $1,100 \pm 150 \mathrm{cpm}$, and that for $\left[{ }^{32} \mathrm{P}\right] \mathrm{PA}$ was $10,060 \pm 703 \mathrm{cpm}$. 
P13P
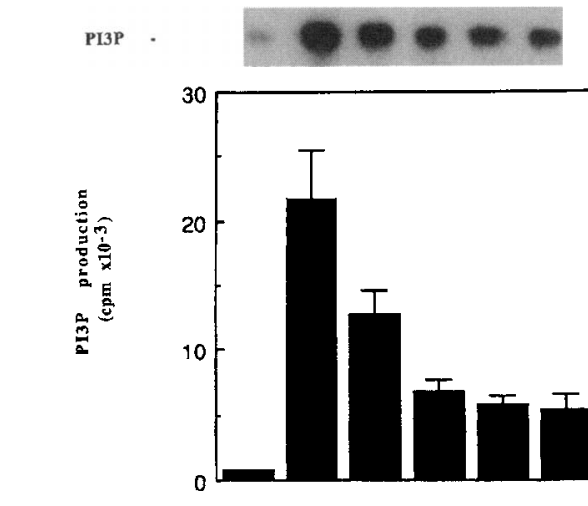

C10-CDP-DAG $(\mu M)$

Insulin

FIG. 6. $\mathrm{C}_{10}$-CDP-DAG inhibits insulin-stimulated PI3K activity in $\mathrm{SH}-\mathrm{SY} 5 \mathrm{Y}$ cells. Cells were preincubated for $60 \mathrm{~min}$ with the indicated concentrations of $\mathrm{C}_{10}$-CDP-DAG and then for an additional 5 min with $100 \mathrm{nM}$ insulin. Anti-phosphotyrosine immunoprecipitates were assayed for PI3K activity as described in Experimental Procedures. The phosphorylated lipid products were separated by TLC, and the corresponding PI phosphate bands were scraped off and quantified by liquid scintillation spectrometry. Lower panel: Data are average + SEM of duplicate determinations and are typical of three separate experiments. Upper panel: Autoradiographs of the region of the thin-layer chromatogram that contained $\mathrm{PI} 3 \mathrm{P}$

within 3 min of incubation and is maximal within 15 min. The decrease in $\left[{ }^{3} \mathrm{H}\right] \mathrm{CDP}-D A G$ level evident by $30 \mathrm{~min}$ of incubation with carbachol is most likely due to further metabolism of CDP-DAG, primarily to PI. The elevation in ${ }^{32} \mathrm{P} \mid \mathrm{PA}$ content precedes that of $\left[{ }^{3} \mathrm{H}\right]$ CDP-DAG, reflecting the biosynthetic sequence in PI resynthesis after carbachol-stimulated breakdown of $\mathrm{PI}(4,5) \mathrm{P}_{2}$. To test directly the possibility that CDPDAG is inhibiting PI3K activity in vivo, we used $\mathrm{C}_{10^{-}}$ CDP-DAG (Benjamins and Agranoff, 1969). Cells were preincubated for $1 \mathrm{~h}$ without or with given concentrations of $\mathrm{C}_{10}$-CDP-DAG and then stimulated with insulin for 5 min. As shown in Fig. 6, a 26-fold stimulation of PI3P formation by insulin was half-maximally reduced by $0.5 \mu M \mathrm{C}_{10}$-CDP-DAG and was maximally blocked at $10 \mu \mathrm{M}$. These values are very close to the $\mathrm{IC}_{50}$ value $(6 \mu M)$ required for inhibition of $\mathrm{PI} 3 \mathrm{~K}$ by CDP-DAG in an in vitro assay system (Lavie and Agranoff, 1996). Addition of $\mathrm{C}_{10}$-PA $(0.01-100 \mu M)$, however, did not affect PI3K activity (data not shown).

\section{DISCUSSION}

PI3K participates in various signal-regulated cell processes induced by mitogenic growth factors and neurotrophic factors (Panayotou and Waterfield, 1992; Parker and Waterfield, 1992; Carter and Downes, 1993; Myers et al., 1994). Stimulation of PI3K activity by insulin in SH-SY5Y neuroblastoma cells resembles that observed with insulin in several other cell prepara- tions, including Chinese hamster ovary cells (Ruderman et al., 1990), adipocyles (Shepherd et al., 1995), and rat liver and skeletal muscle (Folli et al., 1992), and is associated with an increase in anti-phosphotyrosine-immunoprecipitable activity. It is generally accepted that insulin induces an association of the enzyme with tyrosyl-phosphorylated Tyr-Met-X-Met or Tyr-X-X-Met motifs in IRS-1, which increases on insulin stimulation, without an apparent increase in amount of tyrosyl-phosphorylated PI3K (Sung and Goldfine, 1992; Myers et al., 1994). Although there are alternative possible mechanisms for insulin-induced increases in PI3K activity (Carter and Downes, 1993; Myers et al., 1994), the present results indicate that association with IRS-1 also occurs in SH-SY5Y cells. Western blots of insulin-treated cells with antiPI3K antibodies revealed a dramatic increase in the amount of PI3K associated with an anti-phosphotyrosine-immunoprecipitable complex, indicating that the enzyme is associated with tyrosine-phosphorylated proteins in vivo. In accordance with the finding, PI3K activity measured in anti-phosphotyrosine immunoprecipitates was elevated 10-26-fold in insulin-stimulated cells. In contrast, SH-SY5Y cell PI3K protein and activity immunoprecipitated with anti-PI3K antibodies were not measurably affected by insulin treatment (data not shown), in agreement with what has been found in rat HTC cells (Sung and Goldfine, 1992). These results also indicate that the insulin-regulated PI3K activity present in anti-phosphotyrosine immunoprecipitates accounts for only a minor portion of cellular PI3K.

Insulin's principal physiological role in liver and muscle is readily understood, but this is less clear for the nervous system. Receptors for insulin and IGFs are present in various brain regions, and agonist binding leads to increased glucose, uridine, and thymidine uptake, as well as increased ornithine decarboxylase activity (De Pablo and De la Rosa, 1995). Insulin receptors are present also in the SH-SY5Y human neuroblastoma cell line and are known to induce mitogenesis and neurite formation (Recio-Pinto and Ishii, 1988; Mattsson et al., 1990). Although the data indicate that PI3K activation can mediate insulin signal transduction in a brain-derived cell line, it remains to be demonstrated that this insulin-stimulated activity in $\mathrm{SH}_{-}$ SY5Y cells is a component of a mechanism whereby insulin exerts its neurotrophic effects on the CNS (De Pablo and De la Rosa, 1995). It should also be noted that some of the insulin-induced PI3K activity measured in the present study may be mediated by IGF receptors, as IGF receptors are present in $\mathrm{SH}-\mathrm{SY} 5 \mathrm{Y}$ cells (Mattsson et al., 1990) are known to cross-react with insulin receptors (Recio-Pinto and Ishii, 1988) and to activate PI3K (De Pablo and De la Rosa, 1995).

SH-SY5Y cells have been investigated extensively in regard to their muscarinic $\left(\mathrm{M}_{3}\right)$ acetylcholine receptors, which on activation stimulate phosphoinositide turnover (including release of DAG and inositol 1,4,5- 
trisphosphate, followed by PA, and CDP-DAG increases, protein kinase $\mathrm{C}$ activation, and elevation in intracellular $\left[\mathrm{Ca}^{2+}\right]$. In addition to possible roles in prostanoid production and catecholamine release in neurons (Abdel-Latif, 1986), muscarinic receptors have been linked, depending on the cell type examined, to increases (Gutkind et al., 1991 ) and decreases (Conklin et al., 1988) in mitogenesis. Conklin et al. (1988) have found that carbachol caused a marked inhibition of thymidine incorporation into A9 L cells transfected with $M_{1}$ and $M_{3}$ muscarinic receptors, which could be blocked by atropine. Our finding that PI3K activation following insulin addition to intact cells is inhibited by carbachol raised the possibility that the inhibition of mitogenesis by carbachol reflects its inhibition of insulin-induced PI3K activity.

These observations led us to study the nature of carbachol's action on the insulin signal to activate PI3K. Recent studies implicate tyrosine phosphorylation as both an initiator and a possible consequence of muscarinic receptor-mediated PI hydrolysis. Offermanns et al. (1993) have found that stimulation of muscarinic receptors increased tyrosine phosphorylation in SH-SY5Y cells. Thus, we investigated whether or not the tyrosine phosphorylation mechanism of insulin-induced activation of PI3K is altered on carbachol addition. We found that carbachol, either added alone or in the presence of insulin, did not change the amount of PI3K p85 associated with tyrosine-phosphorylated proteins. The availability of anti-p 110 antibody during the course of these experiments prompted us to investigate the possibility that carbachol decreases the insulin-stimulated increase in the amount of p1 10 that is associated with the phosphotyrosine immunocomplex. Unlike the result obtained with anti-p85 shown in Fig. 4 , we found a marked decrease in amount of bound p110. Because p110 is believed to bind to $\mathrm{SH} 2$ domains of $\mathrm{p} 85$ ( Hu and Schlessinger, 1994), it may be that carbachol selectively dissociates the former from the immunocomplex. It is unclear at present whether this represents an independent consequence of activation of the muscarinic receptor or whether the inferred dissociation of the PI3K heterodimer is a consequence of CDP-DAG binding in vivo.

We investigated the effects of exogenously added CDP-DAG and PA, as we recently found that these phospholipid intermediates of the ligand-stimulated phosphoinositide cycle are capable of inhibiting PI3K activity in vitro (Lavie and Agranoff, 1996). We show here that the level of these lipids in intact SH-SY5Y cells is increased on carbachol addition. In accordance with previous studies (Thompson and Macdonald, 1976; Lee et al., 1991), the calculated intracellular concentrations of CDP.DAG and PA after carbachol stimulation (Lavie and Agranoff, 1996) would seem to suffice for potential in vivo regulation of PI3K activity. Addition of the membrane-permeable analogue $\mathrm{C}_{10^{-}}$ CDP-DAG to cells bypasses carbachol-mediated receptor activation and results in a similar extent of inhi- bition as does carbachol. The lack of an analogous effect of added PA may reflect its lesser in vitro inhibitory action relative to CDP-DAG, failure to enter the cells, or its rapid breakdown. CDP-DAG and its analogues appear to enter cells intact (Turcotte et al., 1980). It should be noted that interpretation of these in vivo experiments on the basis of in vitro effects of CDP-DAG do not take into account issues of intracellular compartmentation. Because the levels of CDPDAG in SH-SY5Y cells may vary with the inositol concentration in the culture medium and may be further modified in the presence of $\mathrm{Li}^{+}$(Stubbs and Agranoff, 1993). it will be of interest to examine further PI3K activity under these various conditions. Preliminary results (authors' unpublished data) indicate that constitutive levels of PI3K are decreased under conditions of low medium levels of inositol in the presence of $\mathrm{Li}^{+}$, but no effect is seen on insulin stimulation.

In a prior study (Lavie and Agranoff, 1996), we demonstrated that CDP-DAG does not compete with PI3K's cosubstrates, PI or ATP. Possible effects of higher inositides of the PI 3- and PI 4-series under conditions of hormonal stimulation have not been examined. Of relevance is that PI 3,4,5-1risphosphate has been demonstrated to block PI3K in HIR cells (Rameh et al., 1995). The precise mechanism whereby CDPDAG (or possibly PA) inhibits PI3K is unknown. nor is it presently known whether the apparent dissociation of the PI3K heterodimer seen in insulin-stimulated cells preincubated with carbachol is mediated via increased levels of CDP-DAG or by an independent mechanism. Nevertheless, the finding that such inhibition occurs in vivo gives further credence to the hypothesis that stimulation of the PI4K-mediated pathway, whereby the intracellular messengers inositol 1,4,5-trisphosphate and DAG are generated, may inhibit the PI3K-mediated signal transduction pathway. somewhat paradoxically, via increases in levels of metabolic precursors of PI, the common substrate of both PI3K and PI4K.

Acknowledgment: This work was supported by grant PO1 42652-07 from the National Institutes of Health.

\section{REFERENCES}

Abdel-Latif A. A. (1986) Calcium mobilizing receptors, phosphoinositides, and the generation of second messengers. Phamacol. Rev. 38, 227-272.

Benjamins J. and Agranoff B. W. (1969) Distribution and properties of CDP-diglyecride: inositol transferase from bratin. I. Nellrochein. 16, 513-527.

Carter A. N. and Downes C. P. (1993) Signiling by neurotrophic factors: activation of phosphoinositide 3 -kinase by nerve growth factor. Neuroprotocols 3, $107-118$

Clarke J. F., Young P. W., Yonezawa K.. Kasuga M., and Holnan G. D. (1994) Inhibition of the translocation of GLU11 and GLUt in 3T3-L1 cells by the phosphatidylinositol 3-kinase inhibitor. wortmannin. Biochem. J. 300, 631-635.

Conklin B. R., Brann M. R., Buckley N. J., Ma A. L.. Bonner T. I., and Axelrod J. (1988) Stimulation of arachidonic acid release and inhibition of mitogenesis by cloned genes for muscarinic 
receptor subtypes stably expressed in A9 L cells. Proc. Natl. Acad. Sci. USA 85, 8698-8702.

De Pablo F. and De la Rosa E. (1995) The developing CNS: a scenario for the action of proinsulin, insulin and insulin-like growth factors. Trends Neurosci. 18, 143-150.

Fisher S. K., Heacock A. M., and Agranoff B. W. (1992) Inositol lipids and signal transduction in the nervous system: an update. J. Neurochem. 58, $18-38$.

Folli F., Saad M. J. A., Backer J. M., and Kahn C. R. (1992) Insulin stimulation of phosphatidylinositol 3-kinase activity and association with insulin receptor substrate 1 in liver and muscle of the intact rat. J. Biol. Chem. 267, 22171-22177.

Gutkind J. S., Novotony E. A., Brann M. R., and Robbins K. C. ( 1991 ) Muscarinic acetylcholine receptor subtypes as agonistdependent oncogenes. Proc. Natl. Acad. Sci. USA 88, 47034707

Hawkins P. T., Jackson T. R., and Stephens L. R. (1992) Plateletderived growth factor stimulates synthesis of Ptdlns $(3,4,5) \mathbf{P}_{3}$ by activating a Ptdlns $(4,5) \mathrm{P}_{2} 3-\mathrm{OH}$ kinase. Nature 358, 157-159

Heacock A. M., Stubbs E. B. Jr., and Agranoff B. W. ( 1993) Cytidine-diphosphate diacylglycerol labeling as an index of inositol lipid-mediated signal transduction in brain and neural cells. Neuroprotocols 3, $103-106$.

Hu P. and Schlessinger J. (1994) Direct association of pl $10 \beta$ phosphatidylinositol 3-kinase with $\mathrm{p} 85$ is mediated by an $\mathrm{N}$-terminal fragment of pl 10ß. Mol. Cell. Biol. 14, 2577-2583.

Lavie Y. and Agranoff B. W. (1996) Inhibition of neuroblastoma cell phosphatidylinositol 3-kinase by CDP-diacylglycerol and phosphatidate. J. Neurochem. 66, 811-816

Lee C.. Fisher S. K., Agranoff B. W.. and Hajra A. K. (1991) Quantitative analysis of molecular species of diacylglycerol and phosphatidate formed upon muscarinic receptor activation of human SK-N-SH neuroblastoma cells. J. Biol. Chem. 266, 22837-22846.

Mattsson M. E. K., Hammerling U., Mohall E., Hall K., and Pahlman S. ( 1990) Mitogenically uncoupled insulin and IGF-I receptors of differentiated human neuroblastoma cells are functional and mediate ligand-induced signals. Growth Factors 2, 251-265.

Myers M. G. Jr., Sun X. J., and White M. F. (1994) The IRS-1 signaling system. Trends Biochem. Sci. 19, 289-293.

Offermanns S., Bombien E., and Schultz G. (1993) Stimulation of tyrosine phosphorylation and mitogen-activated-protein (MAP) kinase activity in human SH-SY5Y neuroblastoma cells by carbachol. Biochem. J. 294, 545-550.

Panayotou G. and Waterfield M. D. (1992) Phosphatidylinositol 3 kinase: a key enzyme in diverse signalling processes. Trends Cell Biol. 2, 358-360.

Parker P. J. and Waterfield M. D. (1992) Phosphatidylinositol 3kinase: a novel effector. Cell Growth Differ. 3, 747-752.

Rameh L. E., Chen C.-S., and Cantley L. C. (1995) Phosphatidylinositol $(3,4,5) \mathrm{P}_{3}$ interacts with $\mathrm{SH} 2$ domains and modulates $\mathrm{PI}$ 3-kinase association with tyrosine-phosphorylated proteins. Cell $83,821-830$.

Recio-Pinto E. and Ishii D. N. (1988) Insulin and insulin-like growth factor receptors regulating neurite formation in cultured human neuroblastoma cells. J. Neurosci. Res. 19, 312-320.

Rodriguez-Viciana P., Warne P. H., Ritu D., Vanhaesebroeck B., Gout I. Fry M. J., Waterfield M. D., and Downward J. (1994) Phosphatidylinositol-3-OH kinase as a direct target of Ras. $\mathrm{Na}$ ture 370, 527-532.

Ruderman N. B., Kapeller R., White M. F., and Cantley L. C. (1990) Activation of phosphatidylinositol 3-kinase by insulin. Proc. Natl. Acad. Sci. USA 87, 1411-1415.

Serunian L. A., Auger K. R., and Cantley L. C. (1991) Identification and quantification of polyphosphoinositides produced in response to PDGF stimulation. Methods Enzymol. 198, 78-87.

Shepherd P. R., Nave B. T., and Siddle K. (1995) Insulin stimulation of glycogen synthase activity is blocked by wortmannin and rapamycin in 3T3-LI adipocytes: evidence for the involvement of phosphoinositide 3-kinase and p70 ribosomal protein-S6 kinase. Biochem. J. 305, 25-28.

Stubbs E. B. Jr. and Agranoff B. W. (1993) Lithium enhances muscarinic receptor-stimulated CDP-diacylglycerol formation in inositol-depleted SK-N-SH neuroblastoma cells. J. Neurochem. 60, 1292-1299.

Sung C. K. and Goldfine I. D. ( 1992 ) Phosphatidylinositol 3-kinase is a non-tyrosine phosphorylated member of the insulin receptor signalling complex. Biochem. Biophys. Res. Commun. 189, $1024-1030$.

Thompson W. and Macdonald G. (1976) Cytidine diphosphate diglyceride of bovine brain. Eur. J. Biochem. 65, 107-111.

Turcotte J. G., Srivastava S. P., Steim J. M., Calabresi P., Tibbetts L. M., and Chu M. Y. (1980) Cytotoxic liponucleotide analogs. II. Antitumor activity of CDP-diacylglycerol analogs containing the cytosine arabinoside moiety. Biochim. Biophys. Acta 619, $619-631$. 